\title{
Perancangan Purwarupa Pembangkit Termoelektrik sebagai Media Pembelajaran Konversi Energi
}

\author{
Adlan Bagus Pradana ${ }^{*}$, Fajar Irawan², Andreas Wisnu ${ }^{3}$, Burhan Dwi Saputra ${ }^{4}$, Giri Subakti \\ Muhammad Yusuf ${ }^{6}$, Thalia Roza Yunita ${ }^{7}$ \\ 1,2,3,4,5,6,7 Teknologi Listrik, Departemen Teknik Elektro dan Informatika, Sekolah Vokasi, Universitas Gadjah Mada \\ 1 adlan.pradana@ugm.ac.id* \\ * corresponding author
}

\begin{tabular}{|c|c|}
\hline ABSTRACT & Article Info \\
\hline $\begin{array}{l}\text { Thermoelectric is a device which has the ability to efficiently convert heat energy } \\
\text { into electrical energy. The voltage generated by this thermoelectric is low, so that } \\
\text { it needs to be amplified in order to utilized. Strengthening is done using a DC } \\
\text { Boost Converter. The resulting tool can be used as a medium for learning } \\
\text { renewable energy conversion. }\end{array}$ & \multirow{3}{*}{$\begin{array}{r}\text { Article history } \\
\text { Received: Jan. } 7^{\text {th }}, 2021 \\
\text { Revised: March } 15^{\text {th }}, 2021 \\
\text { Accepted: May } 30^{\text {th }}, 2021 \\
\text { Keywords } \\
\text { thermoelectric, } \\
\text { DC boost converter, } \\
\text { energy conversion, } \\
\text { renewable energy. }\end{array}$} \\
\hline ABSTRAK & \\
\hline $\begin{array}{l}\text { Termoelektrik adalah komponen elektronika yang memiliki kemampuan } \\
\text { mengubah energi panas menjadi energi listrik. Level tegangan yang dihasilkan } \\
\text { oleh elemen termoelektrik ini bernilai rendah. Agar dapat dimanfaatkan, level } \\
\text { tegangan ini perlu melalui proses penguatan terlebih dahulu. Penguatan dapat } \\
\text { dilakukan dengan menggunakan DC Boost Converter. Dengan cara seperti ini, } \\
\text { termoelektrik dapat dimanfaatkan sebagai pembangkit tenaga listrik. Pada } \\
\text { penelitian ini dilakukan perancangan purwarupa pembangkit listrik berbasis } \\
\text { termoelektrik yang dapat dipergunakan sebagai media pembelajaran konversi } \\
\text { energi terbarukan }\end{array}$ & \\
\hline
\end{tabular}

\section{PENDAHULUAN}

Media pembelajaran sangat penting perannya terhadap ketercapaian target pembelajaran mata kuliah. Salah satunya mata kuliah yang ada di Departemen Teknik Elektro dan Informatika (TEDI) UGM adalah Konversi Energi Terbarukan. Media pembelajaran yang dapat dipakai pada mata kuliah ini adalah pembangkit termoelektrik. Pembangkit termoelektrik ini dapat dibuat sendiri dengan menggunakan komponen elektronika sederhana. Pada penelitian ini dilakukan perancangan purwarupa pembangkit termoelektrik.
Termoelektrik adalah piranti yang dapat mengkonversi energi panas menjadi energi listrik. Perbedaan suhu panas dan dingin antar elemen yang ada pada perangkat dapat menghasilkan perbedaan potensial yang dapat dimanfaatkan sebagai sumber listrik. Telah banyak penelitian yang dilakukan terkait pembangkit termoelektrik ini. Nugroho Tri. W., \& Arif R.H. (2016: 485-490) Melakukan uji performansi pendingin termoelektrik pada sistem pendingin peti insulasi alat transportasi ikan segar. Azridjal A., Joko S., \& Villager S (2016:32-38) telah mengaplikasikan pendingin termoelektrik untuk pendinginan beban kecil pada pendingin kotak minuman. Riskha, M.H., Rizky., Mohammad A., \& Ida B (2016: 130- 
136) melakukan perancangan alat pengisian baterai $12 \mathrm{~V}$ untuk keperluan UMKM di Balikpapan untuk proses charging selama 8,33 jam. Yanu, A.S., Dedy K.S., \& Bambang S.K (2016:1-7) membuat sistem pengisi baterai menghindari overcharge oleh PV Panel sehingga pengisian dapat lebih optimal. Hartanto, P., \& Antonius W (2017:33-44) membuat alat prototipe charger baterai menggunakan 3 macam sumber dengan sebuah LCD untuk memonitor jumlah dan arus pengisian baterai. Eko P (2017:148-156) telah berhasil membuat pengisian baterai menggunakan inverter untuk mengefektifkan sistem panel surya pada sepeda listrik niaga. Jojo S., Aa S., \& Muhammad I.P. (2017: 123128) menggunakan termoelektrik generator yang memanfaatkan panas dari kompor tungku untuk lampu penerangan. Dian W., Rino., \& Yazmendra R (2016: 1-8) berhasil membuat kajian eksperimental memanfaatkan termoelektrik sebagai alat multifungsi untuk mendapatkan pemanasan dan pendinginan. Kemudian Reko, R., \& Ayong H (2019: 1-10) Membuat rancangan smart charge baterai untuk menghindari overcharge dan DOD yang dapat diketahui melalui website. Penelitian terbaru dilakukan oleh Muhammad A.P., \& Mahendra W (2020:251-258) yang berhasil membuat prototipe pembangkit listrik termoelektrik generator dengan penghantar panas berupa aluminium, kuningan, dan seng menggunakan sinar matahari.

Pada penelitian ini dirancang sebuah purwarupa pembangkit listrik berbasis termoelektrik dengan tegangan keluaram berkisar $5 \mathrm{~V}$. Nantinya purwarupa ini akan digunakan untuk kepentingan pembelajaran energi terbarukan.

\section{METODE}

Pada penelitian ini dilakukan beberapa tahapan yaitu, studi literatur, perancangan alat, pembuatan alat, trial error, dan pengambilan data
Pada tahapan studi literatur, dilakukan pencarian informasi mengenai segala sesuatu yang berkaitan dengan penelitian. Informasi didapatkan dari penelitian sebelumnya. Didapatkan bahwa hubungan antara perbedaan suhu permukaan termoelektrik dan tegangan keluaran adalah linear sesuai dengan Persamaan Efek Seebeck.

$S=\frac{-V_{T h}}{\Delta T}$

Dimana:

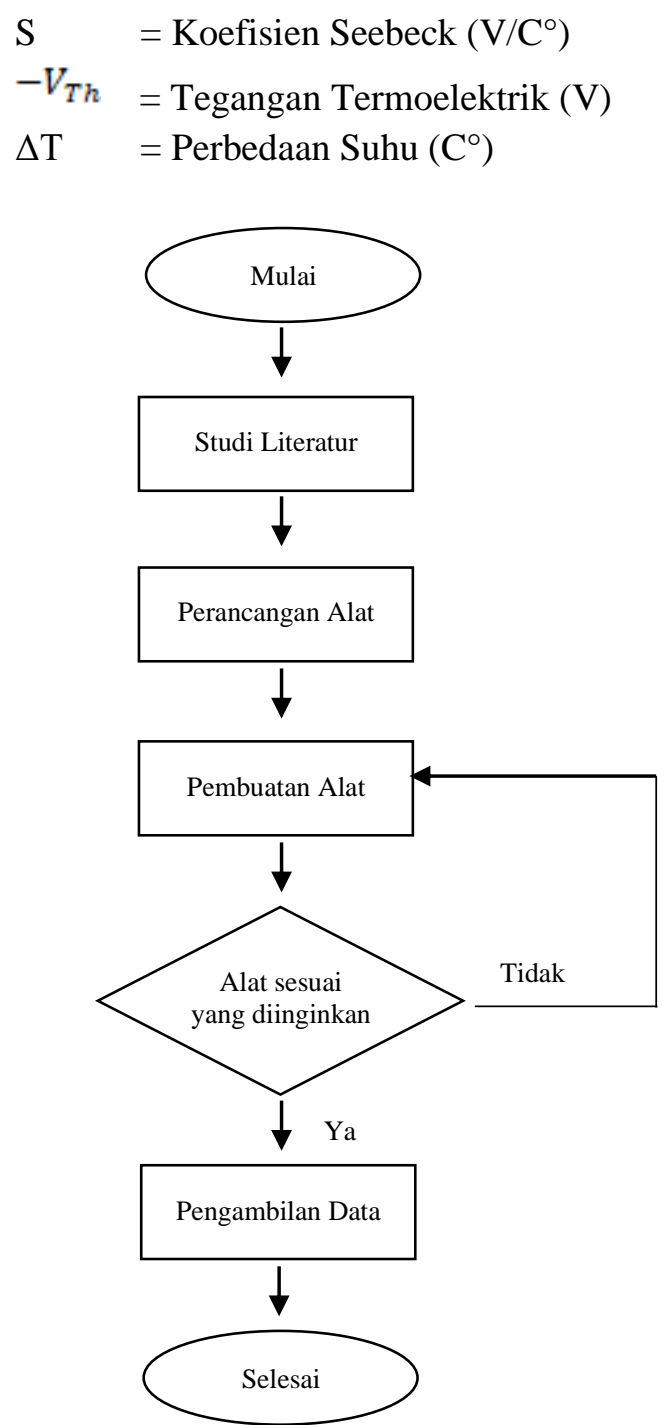

Gambar 1. Diagram Alir Penelitian

Pada tahapan perancangan alat, dilakukan analisis kebutuhan keluaranmasukan, penggambaran sketsa rancangan, dan penentuan komponen yang dibutuhkan. 
Ditentukan bahwa komponen-komponen yang dibutuhkan adalah:

1. Termoelektrik, yaitu untuk mengubah perbedaan suhu menjadi energi listrik.

2. Wadah pembakaran, sebagai tempat meletakkan bahan bakar yang menghasilkan suhu tinggi (panas).

3. Wadah pendingin di sisi bawah termoelektrik yang menghasilkan suhu rendah (dingin).

4. Heatsink berfungsi sebagai penahan pelepas panas

5. DC Boost Step Up menaikkan tegangan keluaran sehingga energi listrik dapat dimanfaatkan.

Pada Gambar 2 dan 3 masing-masing menampilkan sketsa fisik dan rangkaian alat.

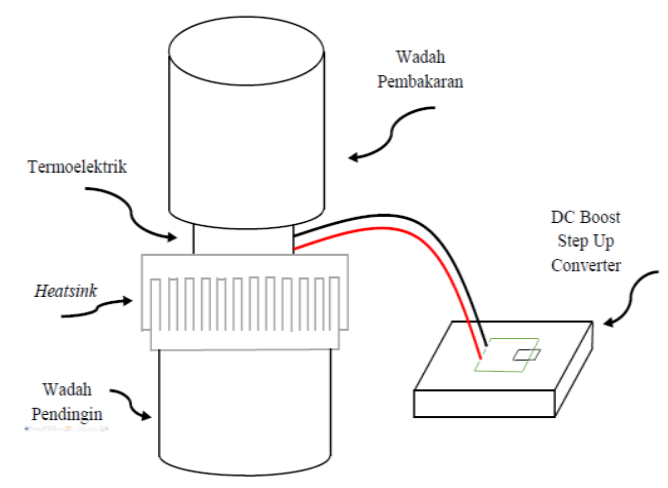

Gambar 2. Sketsa Fisik Alat

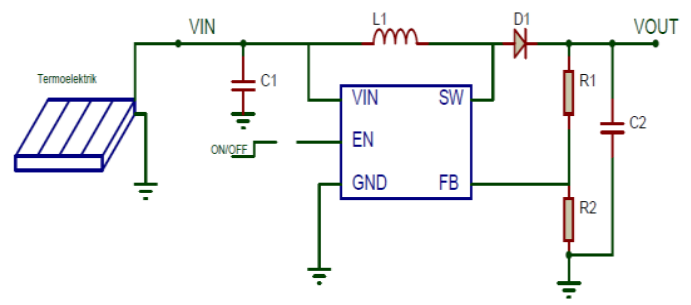

Gambar 3. Rangkaian Alat

DC Boost Step Up yang dipakai berbasis IC MT3608. IC MT3608 adalah IC Boost Step Up 6 pin berbasis MOSFET. IC ini memiliki osilator internal. IC ini juga memanfaatkan tegangan masukan sebagai catu dayanya, sehingga tidak membutuhkan catu daya tambahan.
Tahap berikutnya adalah pembuatan fisik alat. Tahapan ini dilakukan di Laboratorium Teknik Tenaga Listrik Sekolah Vokasi TEDI UGM.

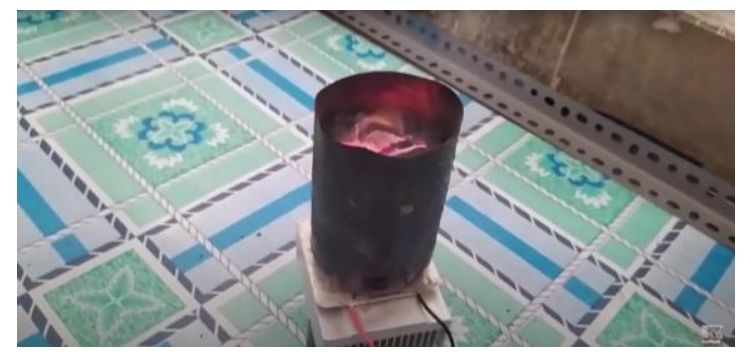

Gambar 4. Proses Pengujian Alat dengan Bahan Bakar Arang

Setelah fisik alat yang dirancang terwujud, dilakukan percobaan. Kekurangan kinerja alat diperbaiki sampai alat bekerja sesuai yang diinginkan. Tahap terakhir adalah pengambilan data. Tahapan ini dilakukan untuk memperoleh karakteristik dari alat yang dirancang.

\section{HASIL DAN PEMBAHASAN}

Bentuk alat tampak samping ditampilkan pada Gambar 5. Pada Gambar 6 menampilkan DC Bost Step Up converter.

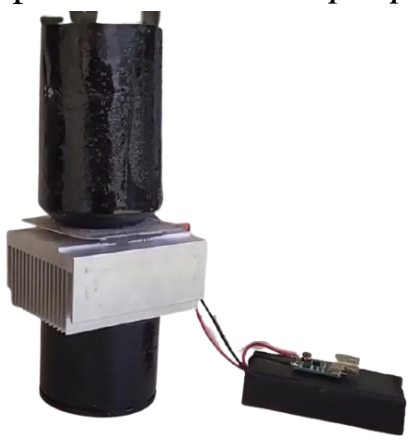

Gambar 5. Bentuk Alat Tampak Samping

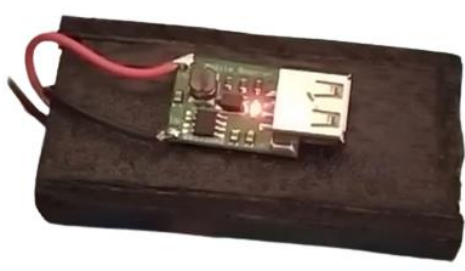

Gambar 6. DC Boost Step Up Converter Out $U S B 5 \mathrm{~V}$ 
Pengujian dilakukan dengan bantuan thermogun untuk mengukur suhu dan multimeter untuk mengukur tegangan keluaran. Wadah pembakaran diisi dengan arang yang dibakar, sementara wadah pendingin diisi dengan es. Didapatkan data sebagaimana tabel 1 di bawah. Pada Gambar 7 ditunjukkan pengukuran output tegangan.

\begin{tabular}{ccc}
\multicolumn{3}{c}{ Tabel 1. Data Suhu dan Tegangan } \\
\hline No & $\begin{array}{c}\text { Perbedaan } \\
\text { Suhu }\left({ }^{\circ} \mathrm{C}\right)\end{array}$ & $\begin{array}{c}\text { Tegangan } \\
(\mathrm{V})\end{array}$ \\
\hline 1 & 30 & 1,00 \\
2 & 32 & 1,50 \\
3 & 34 & 2,00 \\
4 & 36 & 2,85 \\
5 & 38 & 3,12 \\
6 & 40 & 4,00 \\
\hline
\end{tabular}

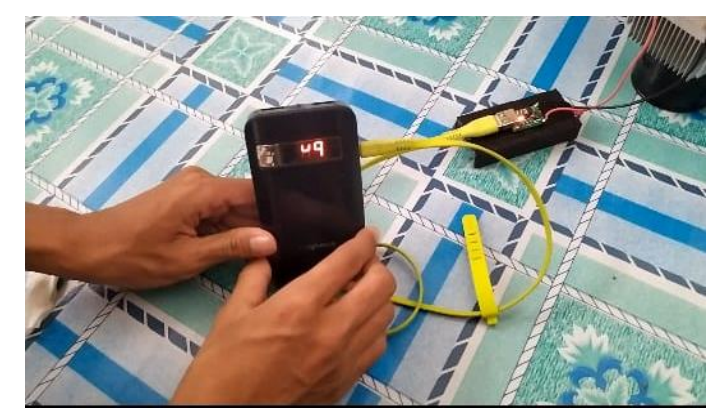

Gambar 7. Pengukuran Output Tegangan

Dari data yang didapatkan, dilakukan analisis regresi linear. Grafik regresi linear antara tegangan dan suhu ditampilkan pada Gambar 8.

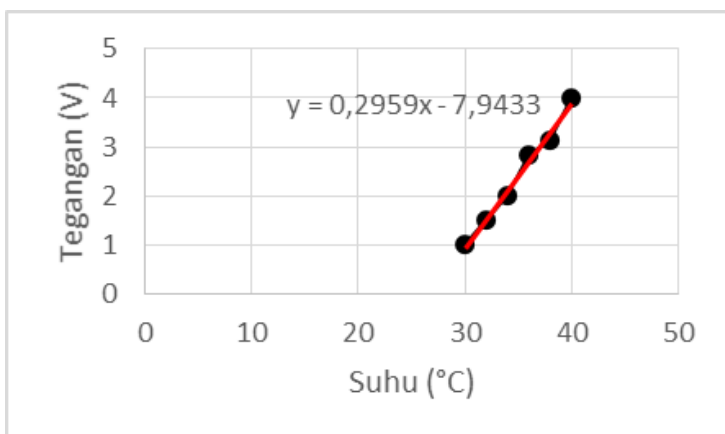

Gambar 8. Grafik Regresi Linear Tegangan dan Suhu
Didapatkan hubungan antara perbedaan suhu permukaan termoelektrik dan tegangan keluaran sebagaimana persamaan (2) berikut.

$V_{T h}=0,2959 \Delta \mathrm{T}-7,9433$

Dimana :

$\begin{array}{ll}V_{T h} & =\text { Tegangan } \operatorname{keluaran}(\mathrm{V}) \\ \mathrm{T} & =\text { Suhu }\left(\mathrm{C}^{\circ}\right)\end{array}$

Nilai Koefisien Seebeck didapatkan sebesar $0,2952 \mathrm{~V} / \mathrm{C}^{\circ}$.

Berdasarkan persamaan (2), terlihat bahwa jika suhu ditingkatkan, maka nilai tegangan keluaran akan tinggi, namun terdapat batasan untuk melakukan hal ini. Batasan yang dimaksud adalah ketahanan dari komponen termoelektrik terhadap panas.

Pada saat pengujian, diinginkan untuk mencapai tegangan sebesar $12 \mathrm{~V}$. Tegangan ini dipandang cukup untuk langsung dimanfaatkan, misalnya untuk untuk mengisi aki. Untuk memperoleh tegangan sebesar ini, dengan menggunakan persamaan (2) perbedaan suhu yang diperlukan adalah sebagaimana berikut.

$12=0,2959 \Delta \mathrm{T}-7,9433$

$\Delta \mathrm{T}=67.39^{\circ} \mathrm{C}$

Namun pada saat melakukan percobaan untuk mencapai nilai tegangan ini, komponen termoelektrik mengalami kerusakan berupa pecah. Hal ini dapat terjadi meskipun rancangan sudah dilengkapi dengan pelepas panas (heatsink). Pada gambar 9 ditunjukkan penggunaan purwarupa pembangkit termoelektrik sebagai peraga pembelajaran energi terbarukan. 


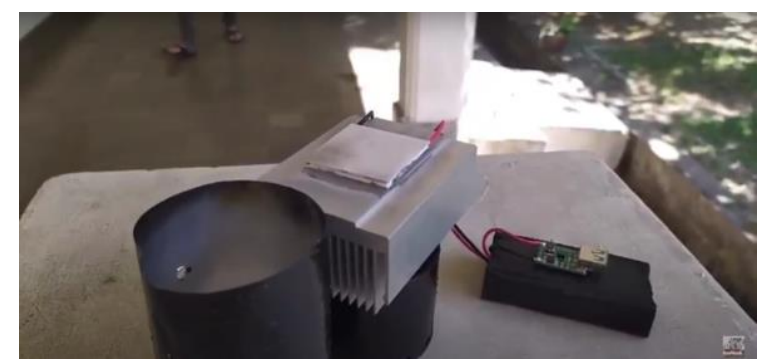

Gambar 9. Penggunaan Purwarupa sebagai

Peraga Pembelajaran Energi Terbarukan

\section{SIMPULAN}

Dari penelitian ini didapatkan bahwa purwarupa berhasil diwujudkan sesuai yang direncanakan. Purwarupa juga telah digunakan sebagai media pembelajaran sebagaimana tujuan utama dari penelitian ini. IC MT3608 bekerja dengan baik dalam meningkatkan tegangan keluaran, sehingga mampu menghasilkan tegangan yang cukup tinggi untuk dapat dimanfaatkan, misalnya untuk mengisi baterai. IC ini juga tidak membutuhkan catu daya tambahan.

Dari penelitian ini dibuktikan pula bahwa hubungan antara perbedaan suhu permukaan termoelektrik berbanding lurus dengan tegangan yang dihasilkan. Faktor pembatas untuk menghasilkan tegangan termoelektrik yang tinggi adalah ketahanan panas termoelektrik. Masih terbuka peluang penelitian lanjutan untuk mengembangkan purwarupa ini sehingga menghasilkan tegangan dan efisiensi yang lebih tinggi. Tegangan yang lebih tinggi dapat dilakukan dengan menyusun termoelektrik secara seri. Sedangkan efisiensi yang lebih tinggi dapat dilakukan dengan menggunakan wadah pembakaran yang terisolasi, sehingga tidak ada panas yang terbuang percuma.

\section{DAFTAR RUJUKAN}

Azridjal A., Joko S., \& Villager S. 2017. Aplikasi Modul Pendingin Termoelektrik Sebagai Media Pendingin Kotak
Minuman. Jurnal Rekayasa Mesin, 10(1), 32-38.

Dian W., Rino., \& Yazmendra R. 2016. Kajian Eksperimental Alat Multi Fungsi Bercatu Daya Termoelektrik Untuk Pendinginan dan Pemanasan. Jurnal Rotor 2, 1-87.

Eko, P. 2017. Pengembangan Solar Panel dan Inverter Sebagai Alat Untuk Charging Baterai Pada Sepeda Listrik. Jurnal Edukasi Elektro 1(2), 148-156.

Hartanto, P., \& Antonius W. 2017. Prototipe Charger Baterai Menggunakan Sumber Energi Matahari, Listrik, dan Mekanik. Widya Teknik, 9(1), 33-44.

Jojo S., Aa S., \& Muhammad I.P. 2017. Pemanfaatan sumber Panas pada Kompor Menggunakan $10 \quad$ Termoelektrik Generator Dirangkai Secara Seri Untuk Aplikasi Lampu Penerangan. SINTEK JURNAL : Jurnal Ilmiah Teknik Mesin, 11(2), 123-128.

Muhammad A.P., \& Mahendra W. 2020. Prototipe Pembangkit Listrik Termoelektrik Generator Menggunakan Penghantar Panas Aluminum, Kuningan, dan Seng. Jurnal Teknik Elektro, 9(2), 251-258.

Nugroho Tri. W., \& Arif R.H. 2016. Performansi Pendingin Termoelektrik Alat Transportasi Ikan Segar Pada Berbagai Tegangan. agriTECH, 36(4), 485-490.

Reko, R., \& Ayong H. 2019. Studi Perancangan Dan Analisis Sistem Pengisian Cerdas (Smart Charge) Baterai. Jurnal Teknik Elektro Universitas Tanjungpura, 2(1), 1-10.

Riskha, M.H., Rizky., Mohammad A., \& Ida B. 2016. Rancang Bangun Charger Baterai Untuk Kebutuhan UMKM. JTT (Jurnal Teknologi Terpadu), 4(2), 130-136.

Yanu, A.S., Dedy K.S., \& Bambang S.K. 2016. Rancang Bangun Sistem Pengisi Baterai 
Lead Acid Berbasis Mikrokontroler Atmega 328 Dengan Sumber Stand-
Alone Pv System. Jurnal Arus Elektro

Indonesia, 2(1), 1-7. 